\title{
The Effects of Body Weight Support on the Locomotor Pattern of Spastic Paretic Patients
}

\author{
M. Visintin and H. Barbeau
}

\begin{abstract}
The effects of mechanically supporting a percentage of body weight on the gait pattern of spastic paretic subjects during treadmill locomotion was investigated. Electromyographic (EMG), joint angular displacement and temporal distance data were simultaneously recorded while 7 spastic paretic subjects walked at $0 \%$ and $40 \%$ body weight support (BWS) at their maximal comfortable treadmill speed. Forty percent BWS produced a general decrease in EMG mean burst amplitude for the lower limb muscles investigated with instances of more appropriate EMG timing in relation to the gait cycle. The joint angular displacement data at $40 \%$ BWS revealed straighter trunk and knee alignment during the weight bearing phase especially at initial foot-floor contact and midstance. An increase in single limb support time and a decrease in percentage total double support time were evident at $40 \%$ BWS. An increase in stride length and maximum comfortable walking speed was also seen with BWS. The use of BWS during treadmill locomotion as a therapeutic approach to retrain gait in neurologically impaired patients is discussed.
\end{abstract}

RÉSUMÉ: Les effets d'un support de poids du corps sur le patron locomoteur chez un groupe de patients paretiques spastiques Cette étude a pour but d'étudier l'effet du support de poids du corps par un système mécanique pendant la marche sur tapis roulant sur le patron de marche chez sept patients ayant une lésion incomplète de la moelle épinière. L'activité électromyographique (EMG) des muscles des membres inférieurs, les données cinématiques et les paramètres du cycle de marche furent enregistrés simultanément. Lorsque $40 \%$ du poids du corps est supporté, une diminution de l'amplitude maximale de la bouffée d'EMG des muscles des membres inférieurs et un profil d'activation EMG plus approprié en relation avec le cycle de marche furent observés. De plus, les données cinématiques ont révélé un meilleur alignement du tronc et du genou au début et au milieu de la phase d'appui. Une augmentation de la durée de la phase de simple appui, de la longeur du pas, de la vitesse maximale comfortable ainsi qu'une diminution de la période de double appui furent également observés. La possibilité de combiner un support progressif du poids du corps avec un entraînement sur tapis roulant est proposée comme nouvelle stratégie d'entraînement locomoteur chez des patients neurologiques.

Can. J. Neurol. Sci. 1989; 16: 315-325

Many of the gait deviations observed in neurologically impaired patients result from their inability to adequately bear weight through their affected lower extremities during the loading phase of the gait cycle. ${ }^{1-3}$ Conventional treatment to retrain gait following a lesion to the central nervous system consists of retraining weight bearing, weight shifting and balance during isolated events of the gait cycle before incorporating these components into the dynamic locomotor task. ${ }^{4-6}$ However, retraining gait under such static conditions appears limited as gait deviations are often seen to persist following such a treatment approach. ${ }^{3,7}$

An alternative approach may be to support a percentage of the patient's body weight while retraining gait under dynamic conditions. As proposed by Finch and Barbeau 8 (1985), this gait retraining strategy would consist of walking the patient on a treadmill at his maximum comfortable speed while a percentage of his body weight is supported centrally at the trunk by an overhead harness (Figure 1). The rationale for this retraining strategy is based on findings from the spinal animal model.

Recovery of locomotor function following a spinal cord transection was considered to be largely dependent on the age of the animal at the time of the lesion.9-11 Until recently, cats spinalized at maturity were described as poor functional walkers with major deficits in their gait pattern. Although they were capable of producing stepping movements with their hindlimbs, they were unable to support their body weight on their hindquarters up to 8 weeks post transection. 12 Recently, the importance of training in accelerating the recovery 13 and maximizing the quality of the locomotor pattern $11,14,15$ in the adult spinal cat has been recognized. Rossignol et al 15 and Barbeau et al ${ }^{13}$ have shown that cats spinalized (T13) as adults could recover a near normal locomotor pattern following an "interactive locomotor

From the School of Physical and Occupational Therapy, McGill University, Montreal

Received October 24, 1988. Accepted in final form May 7, 1989

Reprint requests to: Hugues Barbeau, Ph.D., School of Physical and Occupational Therapy, McGill University, 3654 Drummond Street, Montreal, Quebec, Canada H3G IY5 


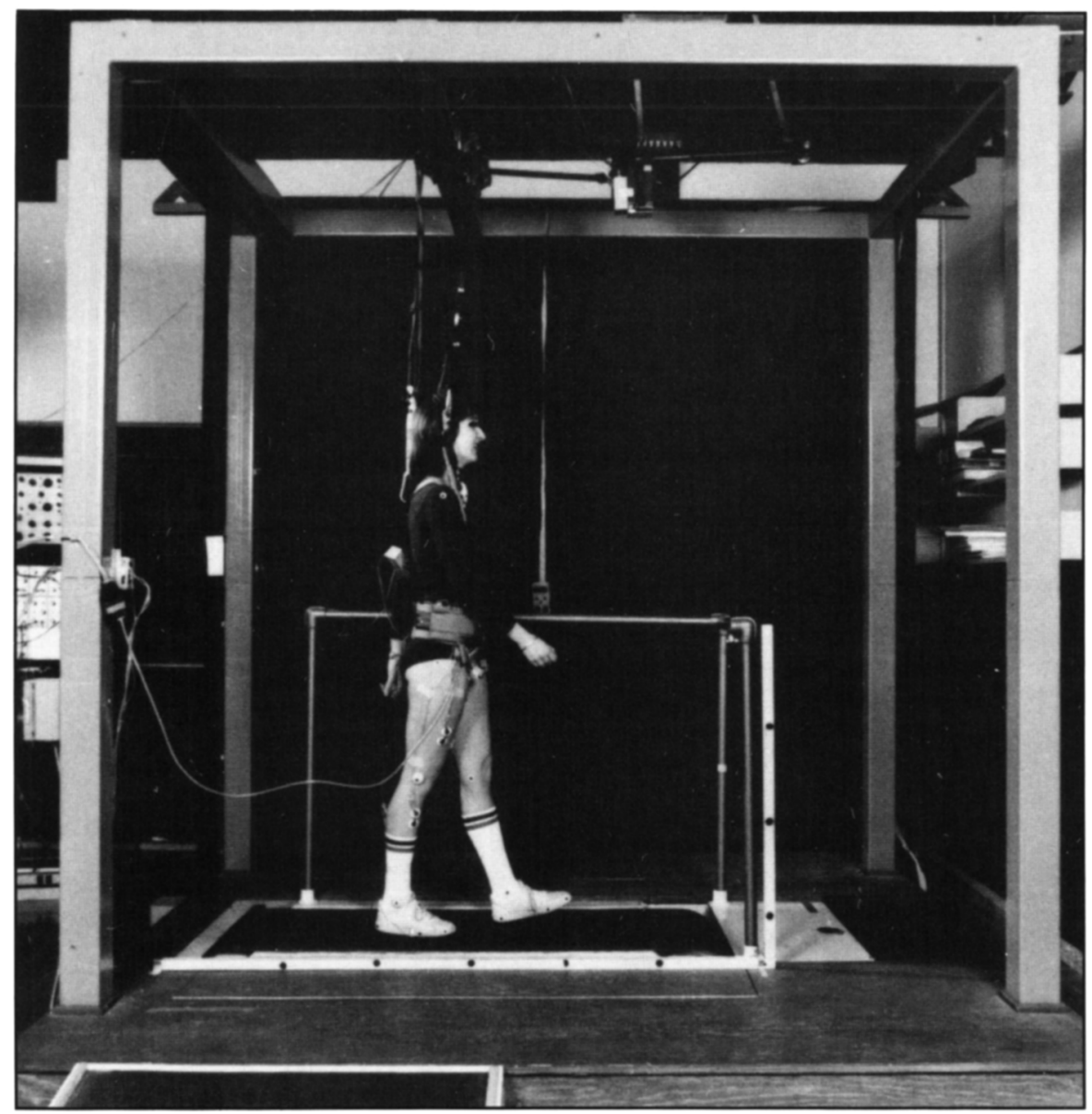

Figure I-A lateral view of the BWS system, consisting of a custom designed harness, which supports the patient over a motorized treadmill.

training" program. During interactive locomotor training, the animal was supported by the tail and allowed to bear only the amount of weight such that it could walk with proper foot placement (with sole of the foot) on the treadmill. Following a period of one to three months of this training regimen the animal was capable of walking at different treadmill speeds, while completely supporting the weight of its hindquarters with proper foot placement. Moreover, the gait pattern was comparable in many aspects to that of the intact adult cat. 16 The authors concluded that interactive locomotor training is an important factor in the recovery of locomotion in the adult spinal cat.

Based on the above animal findings, and clinical observa- tions of inadequate weight bearing among neurologically impaired patients, it has been proposed that supporting a percentage of body weight and progressively decreasing the support while retraining gait may be an effective approach. In order to validate this training strategy, it is important to study the influence that Body Weight Support (BWS) has on neurologically impaired gait. Since spastic paretic subjects have difficulty coping with loading of the lower limbs, ${ }^{17,18}$ such patients have been chosen as the focus for this study. The effects of providing BWS on the electromyographic (EMG), joint angular displacement and temporal distance parameters of spastic paretic gait were investigated.

\section{Table 1: Demographic Data}

\begin{tabular}{|c|c|c|c|c|c|}
\hline Subject & Sex & Age & $\begin{array}{l}\text { Maximal Comfortable } \\
\text { Treadmill Speed } \mathrm{ms}^{-1}\end{array}$ & Lesion Level & $\begin{array}{c}\text { Chronicity } \\
\text { (Years) }\end{array}$ \\
\hline MP & $\mathbf{M}$ & 27 & 0.43 & C4-5 & 3.5 \\
\hline RM & $\mathrm{M}$ & 31 & 0.30 & C6 & 15.0 \\
\hline $\mathrm{BM}$ & $\mathrm{M}$ & 23 & 0.26 & $\mathrm{C} 4$ & $>1.0$ \\
\hline RL & $\mathrm{M}$ & 56 & 0.26 & $\mathrm{~T} 11$ & 1.0 \\
\hline
\end{tabular}

Demographic data of the seven subjects particpating in the study. $\mathrm{C}=$ cervical spine; $\mathrm{T}=$ thoracic spine; $\mathrm{SP}=$ spastic paraparesis. 


\section{METHODS}

\section{Subjects}

The study was conducted in the Human Gait Laboratory which has previously been described. 19 The participants in this study were 7 spastic paretic subjects ranging in age from 23 to 56 years (mean $=36.9$ years). Six of the subjects had sustained trauma-induced incomplete spinal cord lesion to the cervical or thoracic spine while one subject suffered from non-familial progressive spastic paraparesis. The chronicity of the lesion was one or more years for all the subjects (Table 1).

The seven subjects were described as mildly, moderately or severely spastic on the basis of their maximum comfortable treadmill speed and a qualitative visual grading of spasticity during locomotion (i.e. presence of clonus, stiff lower limb movements with decreased angular excursions at 0\% BWS). Two mildly spastic subjects (MP, RP) walked at $0.39 \mathrm{~ms}^{-1}$ and $0.43 \mathrm{~ms}^{-1}$, while two moderately spastic subjects (MB, RM) walked at $0.30 \mathrm{~ms}^{-1}$. The remaining three subjects (BM, RL, SQ) were severely spastic and could only walk at the minimal treadmill speed of $0.26 \mathrm{~ms}^{-1}$. One (BM) of these three subjects was able to walk independently while the other two required manual assistance to advance the left lower extremity.

\section{Body Weight Support}

The subjects walked on a treadmill while $0 \%$ (full weight bearing) and $40 \%$ BWS was provided. Previous experience with the BWS system revealed that providing levels of BWS higher than $40 \%$ resulted in a loss of heel-ground contact for some patients. Hence, $40 \%$ was chosen as the level of support to be investigated. The BWS apparatus (Figure 1) consisted of a custom designed harness which mechanically supported the patient vertically over the treadmill. The harness consisted of a pelvic band attached around the hips and two padded straps which pass between the legs to attach anteriorly to the pelvic band. The percentage of BWS provided was calibrated using a force transducer. The force was normalized to each subject's weight $(100 \%)$ and the sequence of $\%$ BWS provided was randomly assigned into two trials given within the same experimental session. Prior to data collection, each subject was habituated at $0 \%$ BWS for 1 to 5 minutes depending on his walking tolerance. During this trial, treadmill speed was slowly increased from the slowest speed of $0.26 \mathrm{~ms}^{-1}$ to the subjects' maximum comfortable walking speed. This speed was chosen for comparison of the two subsequent BWS trials in order to control for the confounding effect of speed on the gait parameters. Maximum comfortable walking speed at $40 \%$ BWS was also recorded to determine changes with BWS. A 10-minute rest period was given between each trial to prevent fatigue. Blood pressure and pulse were monitored following each trial to control for undue stress on the patients.

\section{EMG and Footswitch Data}

EMG activity was recorded from the vastus lateralis (VL), medial hamstrings $(\mathrm{MH})$, tibialis anterior (TA) and medial gastrocnemius (GA) of the right lower limb while the subject walked on the treadmill. Bipolar surface electrodes $(2.5 \mathrm{~cm}$ centre to centre) were placed over the belly of each muscle following conventional skin preparation. The EMG signals were preamplified, differentially amplified and bandpassed (10-
$450 \mathrm{~Hz}$ ). Footswitches placed under the heel, fifth metatarsal head and big toe of each subject's shoes were used to detect heel strike, foot flat and toe off, allowing for the determination of the temporal distance parameters. The EMG and footswitch signals were then recorded at 3.75 IPS on a 14 channel FM tape with a frequency response of $2500 \mathrm{~Hz}$.

A sequence of artifact-free EMG signals was chosen for analysis. The EMG signals were digitized at $1 \mathrm{KHz}$ for offline computer analysis. They were full wave rectified and low pass filtered with a $3.0 \mathrm{~Hz}$ cut-off frequency to produce analog linear envelopes. The EMG data were synchronized to the normalized stride duration defined as the period from initial foot-floor contact $(0 \%)$ to the subsequent foot-floor contact (100\%). The within-subject ensemble average of 10 strides was used for each muscle as the representative profile for a given subject.

\section{Joint Angular Displacement Data}

Joint angular displacement data were collected from the right lower limb. To do so, the subjects were videotaped as they walked on the treadmill using a shutter video camera. Reflective joint markers were placed at the shoulder, hip, knee and ankle as well as the heel, fifth metatarsal head and toe region of the lateral border of the right shoe. Additional markers were placed on a vertical and a horizontal bar to be used as absolute coordinates for the video analysis. The trials were recorded on a $3 / 4-$ inch video tape at a speed of 60 fields per second. A remote search controller was used for field by field viewing. The sagittal angular displacements were manually measured from the monitor screen using a goniometer. Once the subject had reached a steady state while walking on the treadmill, one representative gait cycle for each subject at each BWS was analyzed. The joint angular displacements were measured at every 2 or $5 \%$ of the gait cycle, depending on the stride duration. The trunk and hip angles were calculated with respect to a vertical line, with the neutral position in standing being taken as $0^{\circ}$ displacement of the trunk and hip, flexion being positive, and extension negative. Likewise, in calculating the knee and ankle angles, the neutral standing position, with the knee at full extension, and the shank axis perpendicular to the foot, was taken as $0^{\circ}$. Knee flexion and ankle dorsiflexion beyond neutral was taken as positive angular displacements, and ankle plantarflexion beyond neutral was taken as negative angular displacement.

\section{Normal Subject}

Data were collected in the same fashion for 10 normal subjects during treadmill walking at their maximum comfortable speed at $0 \%$ BWS. The profiles of EMG activity (averaged across 5 strides ${ }^{20}$ ) and the sagittal angular displacements were similar to those reported previously by various authors for treadmill locomotion. ${ }^{21-23}$ The EMG and kinematic data did not vary extensively between the 10 normal subjects, therefore permitting the illustration of one subject's gait profile (Figure 2) to provide a template against which the pathological gait profiles can be compared.

\section{RESULTS}

The EMG, joint angular displacement and temporal distance data collected for the spastic paraparetic subjects displayed high variability between subjects thus precluding pooling of the 

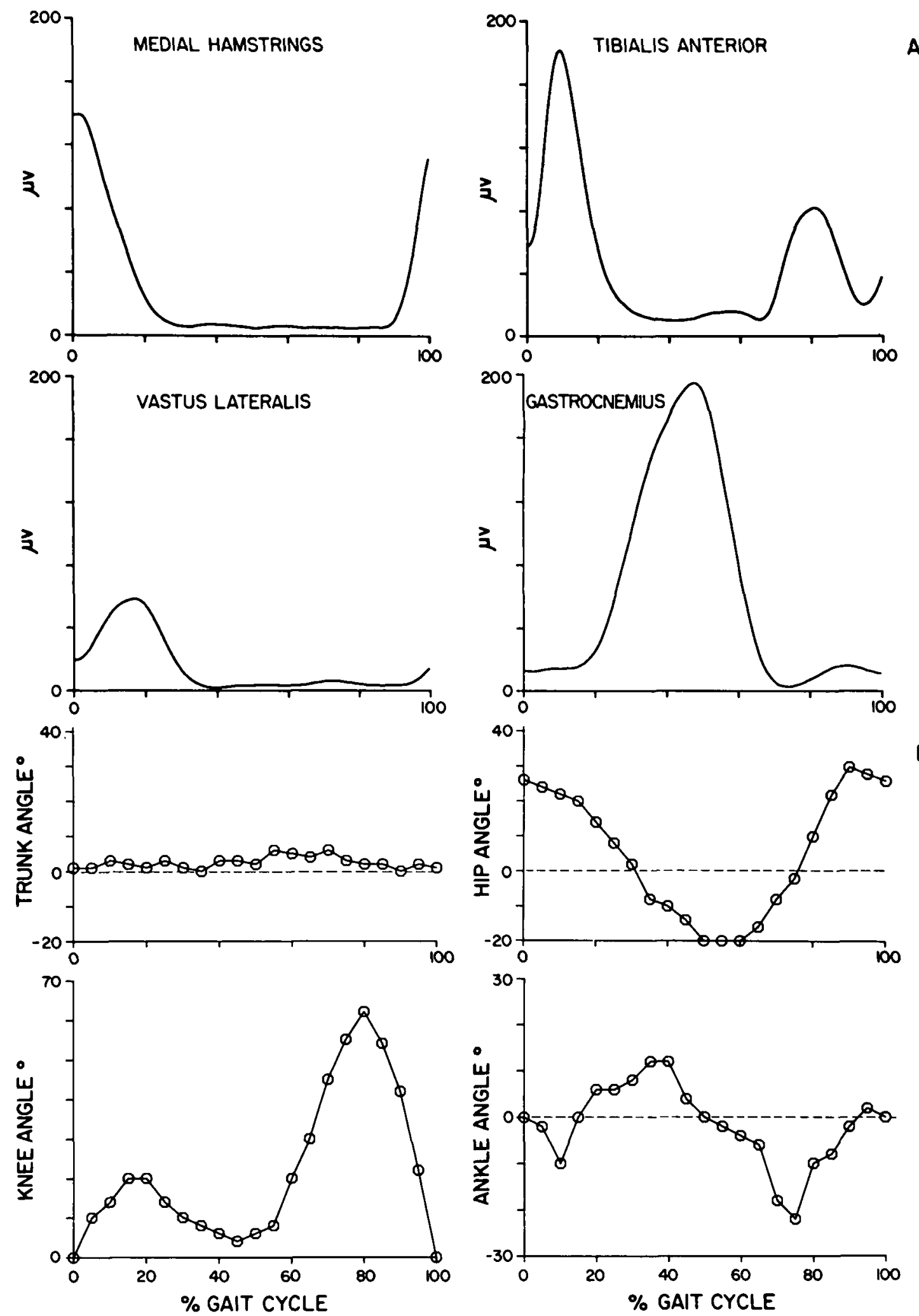

Figure 2-A) EMG mean ensemble averages (across 5 strides) for $M H, V L, T A$ and GA of a normal subject during treadmill walking at 1.36 ms ${ }^{\prime}$ at $0 \%$ BWS and B) corresponding sagittal angular excursions of a representative cycle for the trunk, hip, knee and ankle. 

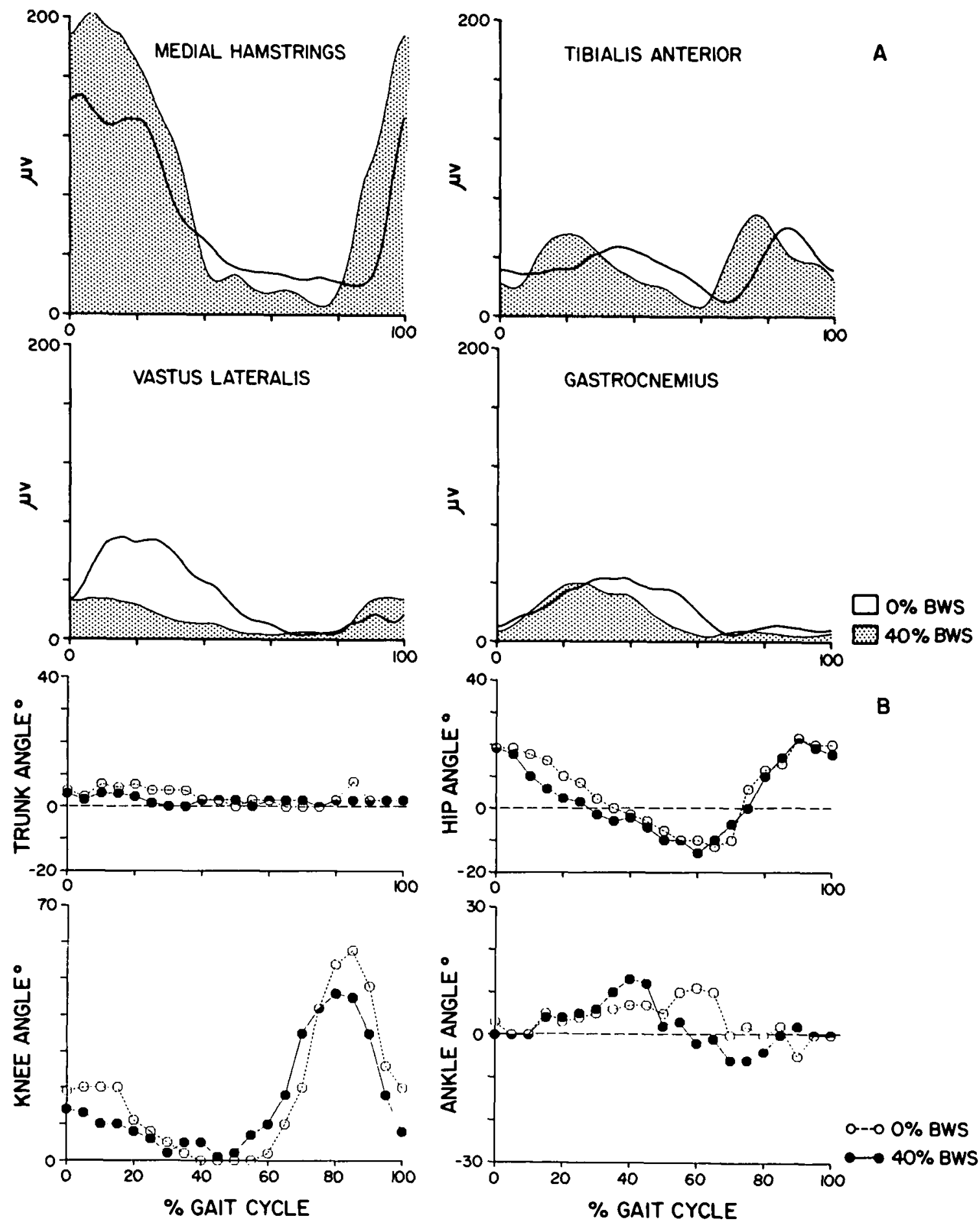

Figure 3-A) Comparison of the MH, VL, TA and GA EMG mean ensemble average (across 10 strides) between 0\% and $40 \%$ BWS trials in a mildly spastic patient (MP) during treadmill locomotion at $0.43 \mathrm{~ms}^{-1}$ and B) the corresponding sagittal angular excursions of a representative cycle for the trunk, hip, knee and ankle. Stance/swing transition at 0\% BWS: $72.6 \%$ gait cycle; at $40 \%$ BWS: $55.4 \%$ gait cycle. 

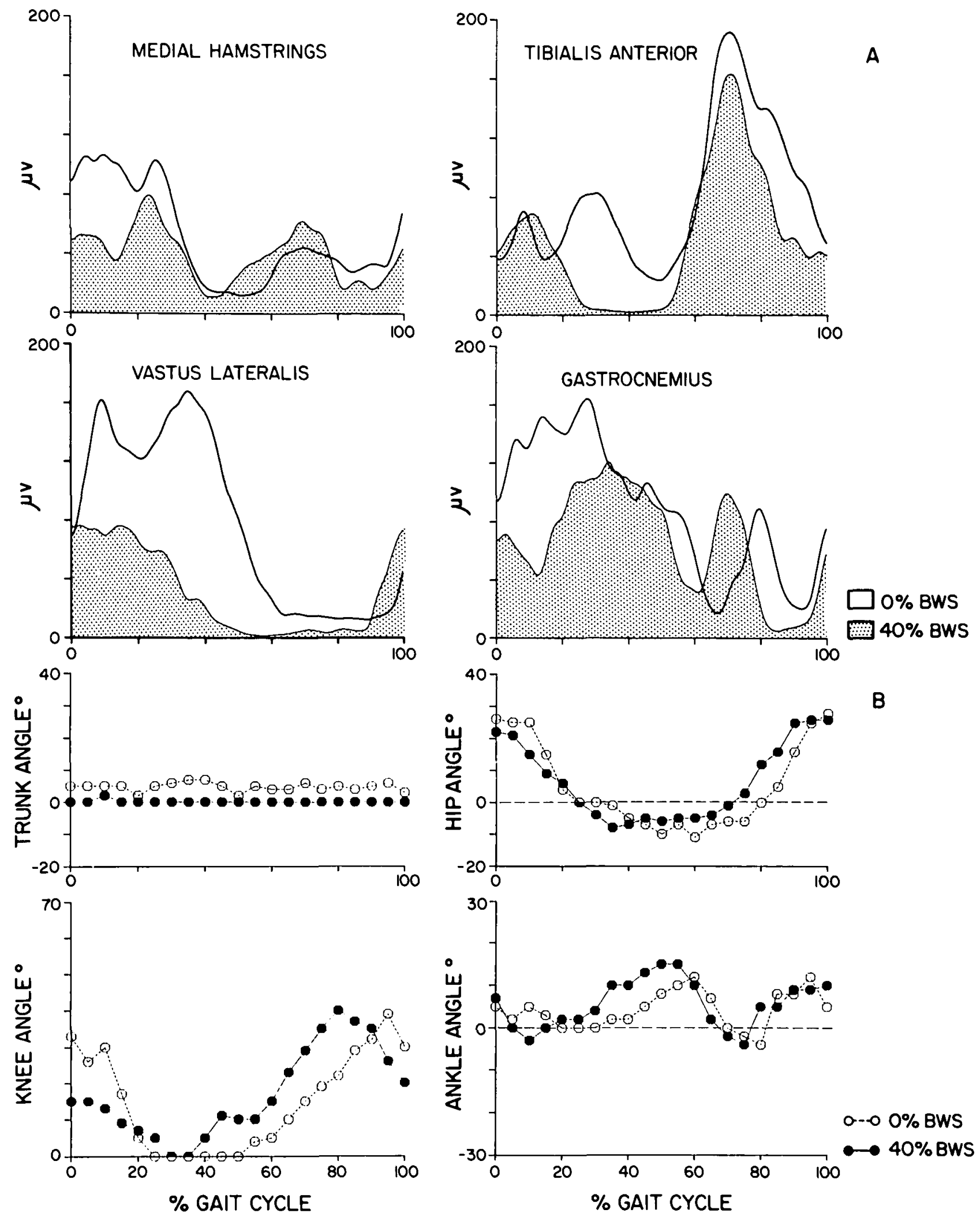

Figure 4-A) Comparison of the MH,VL,TA and GA EMG mean ensemble average (across 10 strides) between 0\% and 40\% BWS trials in a moderately spastic patient $(M B)$ during treadmill locomotion at $0.30 \mathrm{~ms}^{-1}$ and $B$ ) the corresponding sagittal angular excursions of a representative cycle for the trunk, hip, knee and ankle. Stance/swing transition at O\% BWS: $64.1 \%$ gait cycle; at $40 \%$ BWS: $62.4 \%$ gait cycle. 
results for global analysis. Each subject was studied as a descriptive case study. Three of these cases will be described in detail.

\section{Patient 1: MP (Speed $\left.=0.43 \mathrm{~ms}^{-2}\right)$}

The gait profiles described by EMG and joint angular displacement parameters of a mildly spastic subject (MP) walking at $0.43 \mathrm{~ms}^{-1}$ with $0 \%$ and $40 \%$ BWS are contrasted in Figures $3 \mathrm{~A}$ and B. At $0 \%$ BWS this subject's ambulation profiles deviated from that seen in the normal (Figure 2A and B). At 40\% BWS certain gait parameters were modified resulting in a more normal gait. Figure $3 \mathrm{~A}$ shows an increase in amplitude for MH's EMG burst at $40 \%$ BWS as well as a decrease in EMG activity level during the muscle's silent period (between 40 and $80 \%$ of the gait cycle). The main effect of $40 \%$ BWS on VL was to produce a marked decrease in burst amplitude during the stance phase (Figure 3A). A more appropriate EMG profile was noted for TA at $40 \%$ BWS, with the initial burst occurring earlier in the stance phase (Figure $3 \mathrm{~A}$ ) as seen in the normal subject (Figure 2A). GA EMG activity subsided earlier in the gait cycle at $40 \%$ BWS, associated with a decrease in \% stance (Figure 3A; Table 2).

The near normal trunk and hip joint angular displacement profiles at $0 \%$ BWS were not altered at $40 \%$ BWS. The more remarkable improvements at $40 \% \mathrm{BWS}$ were seen at the knee. At heel strike there was a straighter knee alignment with gradual knee extension during midstance (Figure 3B). Qualitatively, subject MP demonstrated a smoother, less spastic gait at $40 \%$ BWS

\section{Patient 2: $\mathrm{MB}$ (Speed $\left.=0.30 \mathrm{~ms}^{-2}\right)$}

Figure 4 depicts the EMG and joint angular displacement profile of a moderately spastic subject, $\mathrm{MB}$. Figure $4 \mathrm{~A}$ illustrates the prolonged activation during the entire stance phase of all 4 muscles at $0 \%$ BWS. At $40 \%$ BWS there was a decrease in amplitude in the initial MH burst, with a small increase in the second burst during the stance to swing transition. At 0\% BWS, VL showed an initial burst of activity occurring within the first $10 \%$ of the gait cycle and a second burst appearing during single limb support at midstance while the limb was fully loaded. At $40 \%$ BWS a remarkable change in EMG profile was evident, with a decrease in burst duration resulting in proper timing relative to the gait cycle as that seen in the normal subject (Figure 2A). In TA the abnormal burst seen during midstance at $0 \%$ BWS was absent at $40 \%$ BWS. The prolonged burst of GA lasting throughout the stance phase was replaced by a profile showing enhanced activity at 0,40 and $70 \%$ of the gait cycle during $40 \%$ BWS. More appropriate timing between TA and GA was also noted with $40 \%$ BWS.

Figure 4B shows the sagittal angular displacement of the trunk, hip, knee and ankle throughout the gait cycle. There was a straighter trunk alignment at $40 \%$ BWS when compared to $0 \%$ (Figure 4B). The hip angular excursion pattern was near normal at $0 \% \mathrm{BWS}$ and remained unchanged with $40 \%$ BWS (Figure $4 B$ ). At 0\% BWS initial foot-floor contact occurred with a flexed knee with subsequent knee extension $\left(0^{\circ}\right)$ being maintained throughout the loading phase. At $40 \%$ BWS, the knee angular excursion pattern approaches that of the normal subject (Figure 2B). A straighter alignment of the knee at heel strike was noted, with progressive extension until midstance, followed by flexion in latter stance and midswing. The maximum swing angle of the knee occurred earlier in the gait cycle $(75 \%)$. The straighter knee alignment at initial foot-floor contact seen at $40 \%$ BWS, allows the dorsiflexed foot to make initial contact with a heel strike rather than the entire sole of the foot as is seen at $0 \%$ BWS (Figure 4B). This change in the sagittal angular displacement of the ankle may be responsible for the more normal GA EMG profile. Following initial foot-floor contact with the entire sole of the foot at $0 \% \mathrm{BWS}$ there was premature stretching of GA as the body moved over an already stationary foot. At $40 \%$ BWS, following heel strike, the dorsiflexed ankle plantarflexed to place the sole of the foot on the ground and GA was shortened early in the stance phase. This delays the stretch on GA to later in the stance phase, as observed in the normal subject. The burst in GA seen at heel strike at $40 \%$ BWS may be due to a stretch on the muscle from the knee being extended and the ankle dorsiflexed. The early recruitment of GA in late swing may also be centrally activated as has been reported in immature gait. ${ }^{24,25}$

\section{Patient 3: BM (Speed $\left.=0.26 \mathrm{~ms}^{-2}\right)$}

Figure 5 presents the data of a severely spastic subject, BM, at $0 \%$ and $40 \%$ BWS. The most marked change in EMG activity was seen in GA where the sustained clonic activity during stance at $0 \%$ BWS was diminished and a burst appeared with proper timing in relation to the occurrence of push-off during the gait cycle (Figure 5A). At $40 \%$ BWS, VL also showed the appearance of a small burst early in the stance

Table 2: Temporal Distance Parameters

\begin{tabular}{|c|c|c|c|c|c|c|c|c|c|c|c|c|}
\hline \multirow{2}{*}{ Subject } & \multicolumn{2}{|c|}{$\begin{array}{l}\text { Cycle Duration } \\
\text { ms }\end{array}$} & \multicolumn{2}{|c|}{$\begin{array}{c}\text { SLST } \\
\text { ms }\end{array}$} & \multicolumn{2}{|c|}{$\underset{\%}{\text { Stance }}$} & \multicolumn{2}{|c|}{$\underset{\%}{\text { TDST }}$} & \multicolumn{2}{|c|}{$\begin{array}{c}\text { Stride Length } \\
\text { cm }\end{array}$} & \multicolumn{2}{|c|}{$\begin{array}{c}\text { Speed } \\
\mathrm{ms}^{-1}\end{array}$} \\
\hline & $0 \%$ & $40 \%$ & $0 \%$ & $40 \%$ & $\mathbf{0 \%}$ & $40 \%$ & $0 \%$ & $40 \%$ & 0\% & $40 \%$ & $0 \%$ & $40 \%$ \\
\hline RP & $\begin{array}{c}1080 \\
(53)\end{array}$ & $\begin{array}{l}1160 \\
(52)\end{array}$ & $\begin{array}{l}337 \\
(45)\end{array}$ & $\begin{array}{l}348 \\
(41)\end{array}$ & $\begin{array}{l}71.3 \\
(2.7)\end{array}$ & $\begin{array}{l}63.1 \\
(2.8)\end{array}$ & $\begin{array}{l}37.7 \\
(3.3)\end{array}$ & $\begin{array}{l}29.6 \\
(4.1)\end{array}$ & 14.0 & 18.0 & 0.39 & 0.43 \\
\hline $\mathrm{RM}$ & $\begin{array}{l}3074 \\
(136)\end{array}$ & $\begin{array}{c}2963 \\
(90)\end{array}$ & $\begin{array}{c}1205 \\
(68)\end{array}$ & $\begin{array}{c}1313 \\
(78)\end{array}$ & $\begin{array}{l}69.3 \\
(1.8)\end{array}$ & $\begin{array}{l}66.3 \\
(1.9)\end{array}$ & $\begin{array}{l}29.0 \\
(1.8)\end{array}$ & $\begin{array}{l}20.6 \\
(2.3)\end{array}$ & 41.0 & 37.0 & 0.30 & 0.31 \\
\hline $\mathrm{BM}$ & $\begin{array}{l}3165 \\
(146)\end{array}$ & $\begin{array}{l}3341 \\
(119)\end{array}$ & $\begin{array}{l}384 \\
(48)\end{array}$ & $\begin{array}{l}631 \\
(90)\end{array}$ & $\begin{array}{l}68.3 \\
(5.6)\end{array}$ & $\begin{array}{l}72.2 \\
(2.2)\end{array}$ & $\begin{array}{l}55.0 \\
(5.3)\end{array}$ & $\begin{array}{l}52.1 \\
(3.8)\end{array}$ & 39.0 & 50.0 & 0.26 & 0.32 \\
\hline $\mathrm{RL}$ & $\begin{array}{l}2230 \\
(205)\end{array}$ & $\begin{array}{l}2608 \\
(143)\end{array}$ & $\begin{array}{c}500 \\
(135)\end{array}$ & $\begin{array}{l}476 \\
(51)\end{array}$ & $\begin{array}{l}85.6 \\
(3.3)\end{array}$ & $\begin{array}{l}81.9 \\
(3.6)\end{array}$ & $\begin{array}{l}61.0 \\
(7.4)\end{array}$ & $\begin{array}{l}62.1 \\
(5.1)\end{array}$ & 21.0 & 30.0 & 0.26 & 0.35 \\
\hline
\end{tabular}

The average cycle duration (ms); single limb support time (SLST) (ms); \% stance; \% total double support time (TDST); and stride length (cm) recorded at $0 \%$ and $40 \%$ BWS at the same treadmill speed are presented. The maximum comfortable treadmill speed (ms ${ }^{-1}$ ) at $0 \%$ and $40 \%$ BWS are also shown. The averages are calculated across 10 strides. The number in parenthesis represents 1 standard deviation. 

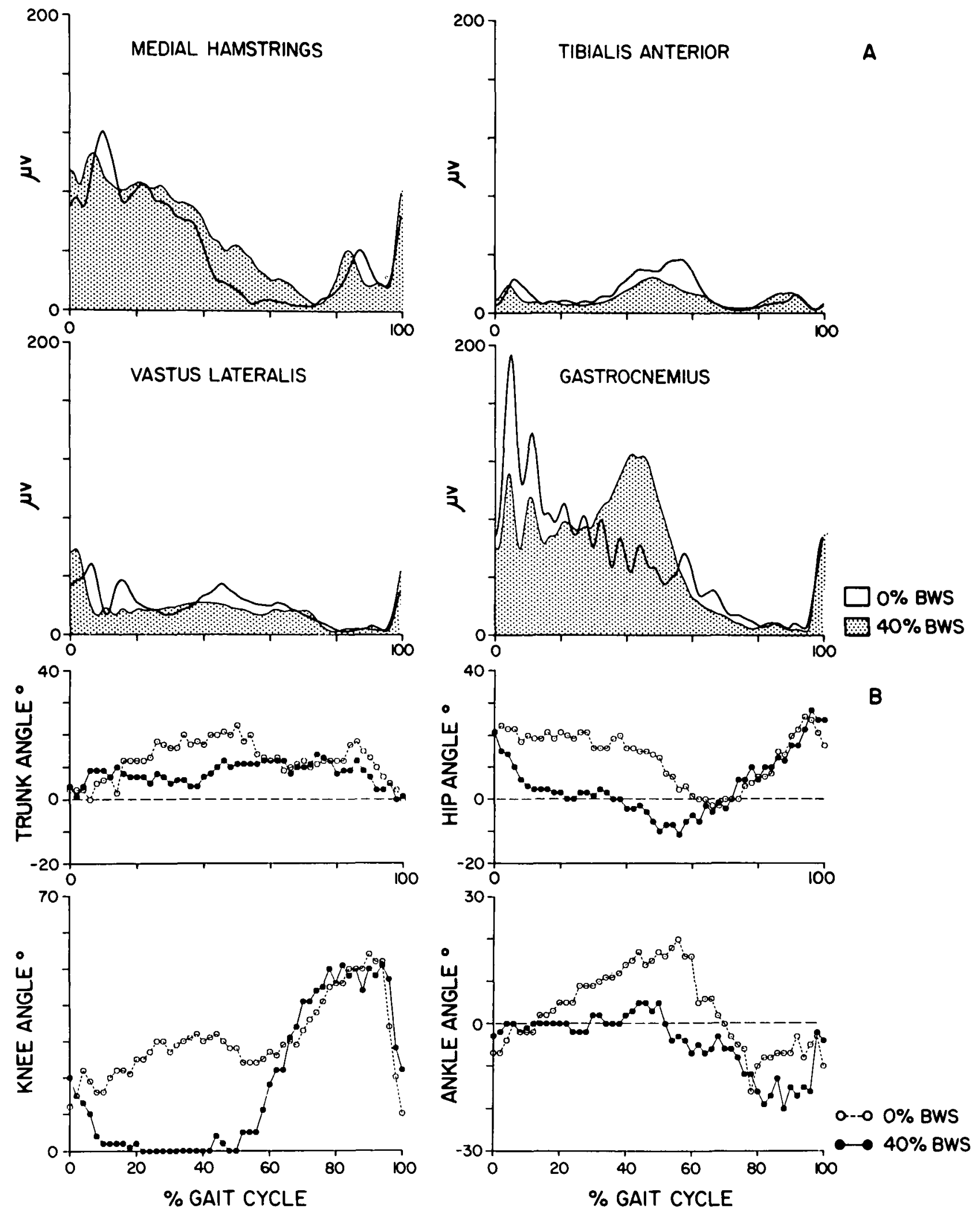

Figure 5-A) Comparison of the MH,VL, TA and GA EMG mean ensemble average (across 10 strides) between $0 \%$ and $40 \%$ BWS trials in a severely spastic patient $(B M)$ during treadmill locomotion at $0.26 \mathrm{~ms}^{-1}$ and $B$ ) the corresponding sagittal angular excursions of a representative cycle for the trunk, hip, knee and ankle. Stance/swing transition at 0\% BWS: $68.3 \%$ gait cycle; at $40 \%$ BWS: $72.2 \%$ gait cycle. 
phase. Minimal changes were noted for MH and TA with BWS.

The important changes in the joint angular displacement patterns seen at $40 \%$ BWS were a straighter trunk alignment during the weight bearing phase and the presence of hip extension (from -2 to $-10^{\circ}$ ) in the latter part of stance and initial swing. At $0 \%$ BWS the knee was main. tained in constant flexion throughout the gait cycle, forcing the ankle into excessive dorsiflexion during the loading phase. This may have been responsible for the sustained clonus seen throughout the stance phase. At $40 \%$ BWS, following initial foot-floor contact with a flexed knee, the knee progressively assumed an extended position during the weight bearing phase resulting in full knee extension during midstance. Associated with the overall decrease in trunk, hip, and knee flexion at $40 \%$ BWS, was a more normal ankle excursion pattern with a decrease in excessive dorsiflexion during mid and late stance (Figure 5B).

\section{Global Effects of the BWS on the 7 Subjects}

In general, there was a decrease in mean burst amplitude for most muscles in all seven subjects, with certain muscles showing a more appropriate EMG timing as evidenced by the examples presented above.

The changes in joint angular displacement patterns seen in the seven subjects revealed that four subjects walking with a flexed posture at $0 \%$ BWS demonstrated a straighter trunk alignment at $40 \%$ BWS. Four of the seven subjects having knee flexion during initial contact at $0 \% \mathrm{BWS}$ showed greater knee extension at $40 \%$ BWS ( 19 to $14^{\circ} ; 28$ to $18^{\circ} ; 35$ to $22^{\circ}$ and 35 to $15^{\circ}$ ). Two out of three subjects having excessive knee flexion during midstance at $0 \%$ BWS gained knee extension at $40 \%$ BWS (22 to $16^{\circ}$ and 35 to $5^{\circ}$ ). Qualitatively, six of the seven subjects demonstrated smoother, freer movements of the lower limbs at $40 \%$ BWS.

Table 2 contains a summary of the temporal distance data collected on the seven subjects while walking on the treadmill at $0 \%$ and $40 \%$ BWS. There was an increase in cycle duration ranging from 5.6 to $20.6 \%$ for six subjects at $40 \%$ BWS. This resulted in an increase in stride length ranging from 13.7 to $42.9 \%$ in these same subjects. Single limb support time was also found to increase in six subjects with increases ranging from 3.3 to $64.3 \%$. A decrease in \% stance with BWS was also noted in 6 subjects. In two of these subjects (MP and RP) the prolonged stance phase approached normal values (55.4 and 63.1 respectively) at $40 \%$ BWS. A further finding was a decrease in percentile total double support time (\% TDST) in 6 subjects with the more marked decreases seen in the mildly and moderately spastic subjects (MP, RP and RM). Another important finding was the ability of the 5 subjects to walk at higher maximal comfortable walking speeds at $40 \%$ BWS. The increase in speed ranged from 10.3 to $44.2 \%$.

All subjects subjectively reported it was easier and less fatiguing to walk at $40 \%$ BWS than at $0 \%$ BWS. This was reflected in their walking tolerance which increased at $40 \%$ BWS, resulting in walking trials which were up to twice as long as at $0 \%$ BWS $(0 \%$ BWS $=2.5 \pm 1.4 \mathrm{~min} ; 40 \%$ BWS $=3.7 \pm$ $2.0 \mathrm{~min})$. All subjects also showed a less elevated heart rate (8 to $19 \%$ ) following the $40 \%$ BWS trial than following the $0 \%$ BWS trial indicating greater cardio-pulmonary efficiency when walking with BWS.

\section{Discussion}

\section{EMG Activity}

The EMG profiles of lower limb muscles of spastic paretic subjects have been described as having early recruitment with prolonged activation during the stance phase. ${ }^{26-28}$ The authors attributed these deviations of the EMG profiles to exaggerated stretch reflexes since most of the activity in the muscles coincided with instances of muscle lengthening during the gait cycle. Four of the subjects in this study revealed prolonged activation of all four lower extremity muscles being investigated throughout the stance phase. Such a pattern of muscle activation can be modified with BWS. As can be seen in MB's GA EMG profile, the prolonged activation seen at $0 \%$ BWS was replaced by a profile showing enhanced activity between 20 and $60 \%$ of the gait cycle required for push-off at $40 \%$ BWS. This is most probably due to the more normal angular excursion occurring at the knee and ankle which could decrease premature stretch on the GA during initial loading.

In the more severely spastic patient (BM), the enhanced stretch reflexes in GA produced sustained clonus during the entire stance phase at $0 \%$ BWS. At $40 \%$ BWS some clonus was still present, but it ceased in mid stance, and a burst of activity in GA appeared between 20 and $60 \%$ of the gait cycle. This coincided with an increase in plantarflexion at the time of pushoff. Decreasing the load on the lower extremities also resulted in a straighter trunk, hip and knee which then allowed the ankle to be in a neutral position during midstance thereby decreasing the stretch on the triceps surae. This may explain the decrease in clonus, thus possibly allowing the GA to be activated and produce a burst for push-off.

Prolonged muscle activation of proximal muscles in spastic paretic gait has also been described by Knutsson. 17.26 He observed prolonged activation in quadriceps and abductor muscles during the stance phase and defined the phenomenon as "crutch spasticity" resulting from a response to load and tonic stretch activation. An example of crutch spasticity can be seen in the VL for subject MB. In this subject the problem of prolonged activation was alleviated by decreasing the load on the lower extremities. At $40 \%$ BWS, VL has a more normal EMG profile, showing a burst of activity early in the stance phase with a definite silent period in late stance.

\section{Joint Angular Displacement Patterns}

The more important changes in joint angular displacement patterns at $40 \%$ BWS were seen during the loading phases of gait. The straighter knee alignment during initial loading and midstance indicated that the subjects were able to bear weight on the lower extremities without assuming the flexed posture which is characteristic of spastic gait. ${ }^{27}$ Therefore, decreasing the load led to more normal joint angular displacement profiles. The occurrence of hip extension in BM at $40 \%$ BWS is an important finding considering that hip extension plays an important role in the initiation of flexion during locomotion. 29 For this subject, the increase in hip extension resulted in an increase in stride length.

\section{Temporal Distance Parameters}

The changes seen in the temporal distance parameters during weight supported locomotion provides further evidence that this strategy allows the patient to cope better with the loading of the lower extremities. The increase in cycle duration and accompanying increase in stride length, seen at $40 \%$ BWS at a constant treadmill speed, indicates that the subjects are able to take 
longer steps. This may be a result of the subject's ability to bear weight on the affected lower extremity for longer periods of time therefore allowing the contralateral limb to take a longer step. Single limb support time (SLST) is a critical component of gait $^{30}$ requiring both the ability to balance and bear weight while the ipsilateral limb is loaded during the swing phase of the contralateral limb. Neurologically impaired gait is characterized by a shortened contralateral swing phase resulting in a shortened SLST of the affected lower limb due to an inability to adequately bear weight. ${ }^{31}$ Six of the spastic paretic subjects in this study showed an increase in SLST at $40 \%$ BWS. This indicated that with BWS the subjects are able to cope with the loading phase of gait and can bear weight on the limb for longer periods of time. At $40 \%$ BWS a decrease in $\%$ TDST was also noted in the majority of subjects. This demonstrates that the subjects may be able to transfer their weight from one limb to the other with greater ease, requiring less support from both limbs during the loading phases.

Speed is a temporal parameter of gait associated with higher levels of lower limb motor recovery ${ }^{31}$ and locomotor function..$^{32}$ Spastic paretic patients walk at speeds considerably lower than normal. ${ }^{27}$ Muscle hypertonia has been suggested as one of the causes for the spastic paretic subject's inability to walk at faster speeds. ${ }^{33}$ The smoother, less spastic gait evidenced at $40 \%$ BWS was accompanied by an increase in comfortable walking speed. This suggests that decreasing load on the lower extremities facilitates locomotion, allowing spastic paretic subjects to walk faster. This may be due, in part, to the decreasing influence of exaggerated stretch reflexes with BWS and may also be related to the increase in stride length, decrease in TDST and increase in SLST which were observed.

\section{New Gait Training Strategy}

It is a common clinical finding that neurologically impaired patients have difficulty weight bearing through their affected lower extremities during ambulation. One of the limitations of conventional gait retraining is that it is done under full weight bearing conditions, most of the time using parallel bars and walking aids to alleviate the load on the lower extremities. A dynamic and task specific approach consisting of progressive weight bearing during treadmill locomotion may be an effective strategy to retrain neurologically impaired gait. The clinical implications and advantages of such a strategy are numerous. The three components of gait: weight bearing, balance and stepping could be retrained simultaneously under dynamic conditions. Gait retraining could be initiated early in the rehabilitation period, providing as much BWS as needed to assume an upright position and allow for assisted or unassisted stepping of the lower limbs. This approach would enable "interactive locomotor training" to be performed. ${ }^{13,15}$ As the patient walks on the treadmill with a reduced load on the lower extremities gait deviations can instantly be corrected and peripheral stimulation can be provided to facilitate muscle activation during the stance or swing phase.

Validation of this novel gait training strategy is in its preliminary stages. The effects of BWS need to be investigated in a larger group of subjects stratified according to the degree of spasticity to determine which subjects would respond more favorably to BWS. The effects of supporting varying levels of BWS from $0 \%$ to $40 \%$ also need to be investigated. This would help to define the criteria by which BWS should be decreased during training. One important issue that needs to be resolved is whether the more normal gait pattern elicited with BWS can be retained and carried over to full weight bearing conditions following a training regimen incorporating BWS where weight bearing through the lower extremities is progressively increased. Preliminary studies suggest that interactive gait training with BWS was important in optimizing the locomotor pattern and achieving full weight bearing in 2 spastic paretic subjects. ${ }^{34}$

\section{CONCLUSION}

BWS during treadmill locomotion in spastic paretic subjects appears to alleviate some of the problems of early stretch and prolonged muscle activation encountered due to their inability to cope with loading under full weight bearing conditions. Decreasing the load on the lower extremities allowed for more normal timing of EMG activity. The straighter trunk and knee alignment during the loading phase, accompanied by a decrease in TDST and an increase in SLST, stride length and speed suggests that BWS facilitates the expression of the locomotor pattern. Consequently it is proposed that the use of BWS during gait training presents potential as a therapeutic approach to retrain gait in neurologically impaired patients.

\section{ACKNOWLEDGEMENTS}

The authors would like to express their thanks to $M$ Wainberg for data collection on the spastic paraparetic subjects and L Finch for data collection on the normal subjects. We would also wish to thank $A B$ Arsenault for critically reviewing the manuscript. This study was supported by MRC and FRSQ. $\mathrm{H}$ Barbeau is a research scholar of the FRSQ.

\section{REFERENCES}

1. Carlsoo S, Dahllof AG, Holm J. Kinematic analysis of the gait in patients with hemiparesis and in patients with intermittent claudication. Scand J Rehab Med 1974; 6: 166-179.

2. Dickstein R, Nissan M, Pillar T, et al. Foot-ground pressure pattern of standing hemiplegic subjects: Major characteristics and patterns of improvement. Phys Ther 1984; 64: 19-23.

3. Wall JC, Turnbull GI. Gait asymmetries in residual hemiplegia. Arch Phys Med Rehab 1986; 67: 550-553.

4. Guttman L. Spinal injuries. Comprehensive management and research. Blackwell Scientific Publications: Osnery Mead, Oxford 1976.

5. Johnson M. The stroke patient. Principles of Rehabilitation. Edinburgh, Scotland: Churchill Livingstone Inc 1976.

6. Bobath B. Adult hemiplegia: Evaluation and Treatment, 2nd edition, London, England: Heinnemann Medical Books 1978.

7. Bogardh $E$ and Richards C. Gait analysis and relearning of gait control in hemiplegic patients. Physiother Can 1981; 33: 223230.

8. Finch L and Barbeau $H$. Hemiplegic gait: New treatment strategies. Physiother Can 1985; 38: 36-41.

9. Grillner S. Locomotion in the spinal cat. In: Stein RB, Pearson KG, Smith RS, Redford JB, eds. Control of Posture and Locomotion. New York: Plenum Press 1973: 515-535.

10. Forssberg H, Grillner S, Halbertsma J. The locomotion of the low spinal cat I: Coordination within a hindlimb. Acta Physiol Scand 1980; 108: 269-281.

11. Smith JL, Smith A, Zernicke RF, et al. Locomotion in the exercised and non-exercised cats cordotomized at 2 and 12 weeks of age. Exp Neurol 1982; 16: 393-413. 
12. Eidelberg E, Story JL, Meyer BL, et al. Stepping by chronic spinal cats. Exp Brain Res 1980; 40: 241-246.

13. Barbeau H, Rossignol S. Recovery of locomotion after chronic spinalization in the adult cat. Brain Res 1987; 412: 84-95.

14. Lovely RG, Gregor RJ, Roy RR, et al. Effects of training on the recovery of full-weight-bearing stepping in the spinal adult cat. Exp Neurol 1986; 92: 421-435.

15. Rossignol S, Barbeau H, Julien $\mathrm{C}$. Locomotion of the adult chronic spinal cat and its modifications by monoaminergic agonists and antagonists. In: Goldberger ME, Gorio A, Murray M, eds. Development and Plasticity of the Mammalian Spinal Cord. Padova: Liviana Press Fidia Research Series, 1986: 323-345.

16. Engberg I, Lundberg A. An electromyographic analysis of muscular activity in the hindlimb of the cat during unrestrained locomotion. Acta Physiol Scand 1969; 75: 614-630.

17. Knutsson E. Analysis of gait and isokinetic movements for evaluation of antispastic drugs or physical therapies. $I n$ : Desmedt JE, ed. Motor Control Mechanisms in Health and Disease. New York: Raven Press 1983: 1013-1034.

18. Barbeau H, Fung J, Stewart J, et al. Impairment of spastic paraparetic gait: Implications for new rehabilitation strategies. Proceeding of the fifth biennial conference and human locomotion symposium of the Canadian Society for Biomechanics. 1988: 12-16.

19. Barbeau H, Wainberg M, Finch L. Description and application of a system for rehabilitation. Med Biol Eng Comput 1987; 25: 341 344.

20. Arsenault AB, Winter DA, Marteniuk RG, et al. How many strides are required for the analysis of electromyographic data in gait? Scand J Rehab Med 1986; 18: 133-135.

21. Thorstensson A, Nilsson J, Carlson $\mathrm{H}$, et al. Trunk movements in human locomotion. Acta Physiol Scand 1984; 121: 9-22.

22. Murray MP, Spurr GB, Sepic SB, et al. Treadmill vs floor walking: kinematics, electromyogram and heart rate. J Appl Physiol 1985; 59: 87-89.

23. Arsenault $A B$, Winter $D A$, Marteniuk RG. Treadmill versus walkway locomotion in humans. An EMG study. Ergonomics 1986; 29: 665-676.
24. Sutherland DH, Olshen R, Les Cooper BA, et al. The development of mature gait. J Bone Joint Surg 1980; 62-A: 336-353.

25. Forssberg H. Ontogeny of human locomotor control I. Infant stepping, supported locomotion and transition to independent locomotion. Exp Brain Res 1985; 57: 480-493.

26. Knutsson E, Richards C. Different types of disturbed motor control in gait of hemiparetic patients. Brain 1979; 102: 405-439.

27. Conrad B, Benecke R, Meinck HM. Gait disturbances in paraspastic patients. In: Delwaide PJ, Young RR, eds. Restorative Neurology, Vol 1. Clinical Neurophysiology in Spasticity. Netherlands: Elsevier Science Publishers B.V. (Biomedical Division) 1985: 155-174.

28. Benecke R, Conrad B, Disturbances of posture and gait. In: Bles W, Brandt TH, eds. Disorders of Posture and Gait. Netherlands: Elsevier Science Publishers B.V. (Biomedical Division) 1986: 217-229.

29. Grillner S, Rossignol S. On the initiation of the swing phase of locomotion in chronic spinal cats. Brain Res 1978; 146: 269277.

30. Perry J. The mechanics of walking in hemiplegia. Clin Orthop 1969; 63: 23-31.

31. Brandstater ME, de Bruin $\mathrm{H}$, Gowland $\mathrm{C}$, et al. Hemiplegic gait: Analysis of temporal variables. Arch Phys Med Rehabil 1983; 64: 583-587.

32. Mizrahi J, Susak Z, Heller L, et al. Objective expression of gait improvement of hemiplegics during rehabilitation by time-distance parameters of the stride. Med Biol Eng Comput 1982; 20: 628-634.

33. Dietz V. Impaired reflex control of posture and gait in spastic paresis. In: Bles W, Brandt TH, eds. Disorders of Posture and Gait. Netherlands: Elsevier Science Publishers B.V. (Biomedical Division) 1986: 243-252.

34. Fung J, Stewart J, Barbeau H. The combined effect of clonidine and cyproheptadine with interactive locomotor training on spastic paraparetic gait. Soc Neurosci Abstr 1988; 14: 263. 